Original Article

\title{
A SYSTEM ATIC EVALUATION OF RAPID DOT-EIA, BLOOD CULTURE AND WIDAL TEST IN THE DIAGNOSIS OF TYPHOID FEVER
}

\author{
Sanjeev $\mathbf{H}^{1}$, Sweetha Nayak', Pai Asha K.B. ${ }^{3}$, Rai Rekha ${ }^{4}$, Vimal Karnaker ${ }^{5} \&$ Ganesh H.R. ${ }^{2}$ \\ ${ }^{1,3}$ Assistant Professors, ${ }^{2}$ Tutors, ${ }^{4}$ Associate Professor, ${ }^{5}$ Professor \& Head, \\ Department of Microbiology, K.S. Hegde Medical Academy, Nitte University, M angalore - 575 018. India. \\ Correspondence: \\ Sanjeev H. \\ Assistant Professor \\ Department of M icrobiology, K.S. Hegde M edical Academy, Nitte University, M angalore - 575 018, Karnataka, India \\ Phone: +91 824 2204490/92. M obile : +91 9972212280 E-mail : drsanjeevh@ gmail.com
}

\begin{abstract}
:
Background : Typhoid fever, caused by Salmonella enterica serotype Typhi, is endemic in the Indian sub-continent including Bangladesh, South-east and Far-east Asia, Africa and South Central America. The disease can occur in all age group with highest incidence among children. Blood culture is regarded as the gold standard for diagnosis and carry $70-75 \%$ diagnostic yield in the first week of illness. However, this requires laboratory equipment and technical training that are beyond the means of most primary health care facilities in the developing world. Typhidot is a rapid dot-enzyme immune assay (EIA), which detects IgG and IgM antibodies to a specific $50 \mathrm{kD}$ outer membrane protein (OM P) antigen of Salmonella enterica serotype Typhi. Typhidot becomes positive as early as in the first week of fever. The results can be visually interpreted and is available within one hour.
\end{abstract}

M aterials and method : Fifty blood samples, collected aseptically from patients clinically diagnosed of Typhoid fever, were evaluated by blood culture, Widal test and Typhidot.

Results : Of the 50 patients, $33(66 \%)$ were positive by blood culture. Widal test was positive in 33(66\%) patients which included 26 in blood culture positive patients and 7 in blood culture negative patients. Typhidot was positive in 37 (74\%) patients. Thus, in comparison to the gold standard test i:e blood culture, Typhidot and Widal test had sensitivity and specificity of $100 \% \& 76 \%$ and $78.78 \% \& 58.82 \%$ respectively.

Conclusion : Typhidot is found to have high sensitivity and good specificity and could be applied as a good alternate in resource poor nation. Further, it is simple to perform, reliable when compared to Widal test, and rapid, with results being available in one hour when compared to 48 hours for blood culture and 18 hoursfor Widal test.

Key words: Typhidot, Blood culture, Widal, Salmonella enterica

\section{Introduction :}

Typhoid fever, caused by Salmonella enterica serotype Typhi, is a major cause of morbidity and mortality worldwide, causing an estimated 16.6 million new infections and 600,000 deaths each year. ${ }^{1}$ It is endemic in the Indian subcontinent including Bangladesh, South-east and Far-east Asia, Africa and South Central America. The disease can

\begin{tabular}{|c|}
\hline Access this article online \\
\hline Quick Response Code \\
\hline
\end{tabular}
occur in all age group with highest incidence among children. ${ }^{2}$ The annual incidence of typhoid fever has been reported asmore than 13 million cases in Asia. $^{3}$
Isolation of Salmonella from blood, urine or stool is the most reliable means of confirming an infection. Blood culture is regarded as the gold standard for diagnosis and carry $70-75 \%$ diagnostic yield in the first week of illness. ${ }^{4}$ However, this requires laboratory equipment and technical training that are beyond the means of most primary health care facilities in the developing world. ${ }^{1}$ In addition, easy availability and widespread use of antibiotics in the community makes it frequently difficult to isolate the organism from blood culture and alternate methods such as bone marrow cultures may be required, which is invasive and difficult to carry out. ${ }^{2}$

Thus one has to rely on serological diagnosis, which is the mainstay of diagnosis of typhoid fever in most laboratories 
in developing world. ${ }^{5}$ Unfortunately, neither the Widal test, which remains in widespread use in the developing world, nor any of the serodiagnostic tests that have since been developed has proven sufficiently sensitive, specific and practical to be of value in areas where this disease is endemic. ${ }^{1}$

Typhidot is a rapid dot-enzyme immune assay (EIA), which detects IgG and IgM antibodies to a specific $50 \mathrm{kD}$ outer membrane protein (OMP) antigen of Salmonella enterica serotype Typhi. Typhidot becomes positive as early as in the first week of fever, the results can be visually interpreted and is available within one hour. ${ }^{6}$

This study was undertaken to systematically evaluate the utility of Typhidot in diagnosis of typhoid fever in terms of sensitivity and specificity.

\section{Materials and methods:}

The study was conducted in the Department of Microbiology, K.S. Hegde Medical College and Hospital, located in M angalore. Blood was collected from 50 patients who were clinically diagnosed with typhoid fever.

Ten $\mathrm{ml}$ of blood was inoculated into blood culture media (BHI broth) and incubated at $37^{\circ} \mathrm{C}$. Subcultures were done on every alternate day till the $7^{\text {th }}$ day. The growth of Salmonella was identified as per standard protocol and confirmed by agglutination with Salmonella polyvalent "O", "O" 9 and $H:$ ' $d$ ' antisera. ${ }^{7}$ The Widal test was performed by tube agglutination method and it was considered positive when a titre of equal to or more than 1:160 was observed. ${ }^{8}$ Typhidot is a rapid, qualitative test which detects specific IgG and IgM antibodies to a specific 50-kD OM P antigen on Salmonella typhi enterica serotype Typhi strains. The test was done as per manufacturer's kit instructions (Typhidot; Malaysian Biodiagnostic Research SDN BHD, Kuala Lumpur, Malaysia). Reaction tray was divided into two columns and marked " $\mathrm{M}$ " and " $\mathrm{G}$ " and strips were placed respectively. $250 \mu$ l of the sample diluents was then added to reaction wells. $2.5 \mu$ l of control/test serum was added to each well and incubated for 20 minutes at room temperature on a rocker platform.
The strip was washed thrice and $250 \mu \mathrm{I}$ Anti human Ig M and Anti human IgG conjugates were added to respective wells and incubated for 15 minutes. The strip washed as before, and $250 \mu \mathrm{l}$ of colour development solution was added and incubated for another $15 \mathrm{~min}$. The reaction was stopped, the strip was washed in distilled water and the result was read. When both the dots on the test strip were as dark as or darker than their corresponding dots on the positive control strip, they were reported as positive. The absence of visible spot indicated a negative test result. If the spots were fainter than control, that sample was also considered negative, as per directions given in the kit. In case of discrepant appearance of duplicate spots the test was repeated and only if both spots were darker than control, the sample was considered positive.

\section{Results:}

Fifty blood samples were evaluated for typhoid fever by blood culture, Widal test and Typhidot. Of the 50 patients, $33(66 \%)$ were positive by blood culture. Salmonella enteric serotype Typhi was isolated in 30 patients where as Salmonella enteric serotype Paratyphi A was isolated in 3 patients. Widal test was positive in $33(66 \%)$ patients which included 26 in blood culture positive patients and 7 in blood culture negative patients. Typhidot was positive in 37 (74\%) patients. Of the 37 Typhidot positive cases 30 were positive for both IgG and IgM antibodies, 4 for IgG antibodies only and 3 for IgM antibodies only. Of the 37cases positive by Typhidot, 33 were also positive by blood culture and 4 were negative by blood culture. These 4 patients who were negative on blood culture but positive by Typhidot were also positive by Widal test. Thus, in comparison to the gold standard test i:e blood culture, Typhidot and Widal test had sensitivity and specificity of $100 \% \& 76 \%$ and $78.78 \% \& 58.82 \%$ respectively.(Table 1 , Table 2). A comparison of Widal and Typhidot is described in Table 3.

\section{Discussion :}

Typhoid fever is a systemic illness with a significant morbidity and mortality in developing countries. ${ }^{9}$ Emergence of multidrug resistant strains of Salmonella 
enterica serotype Typhi has only added to the burden of the disease. Any delay in diagnosis and institution of appropriate therapy only increases the risk of outcome. ${ }^{2}$

Blood culture has remained the gold standard for diagnosis of typhoid fever. Of the 50 patients clinical diagnosis of typhoid fever evaluated, 66\% (33/50) were positive by blood culture. Of the 33 positive blood cultures, 30 were Salmonella enterica serotype Typhi and 3 were Salmonella enterica serotype Paratyphi A. This rate of isolation for blood culture correlates well documented data, which reports sensitivity of $65-68 \% .{ }^{9}$ The high rate of isolation in the present study could be attributed to a) awareness among people leading to early presentation to secondary or tertiary health care facility, b) the present study involved adult population thus adequate quantities of blood could be taken for diagnostic test and c) improvements in blood culture methods especially use of automated systems. While, in contrast to the present study, many reports have quoted sensitivity ranging from $8.9-43 \%{ }^{5,10-14}$ The relative low rate of isolation from blood culture had been attributed to delay in diagnosis, widespread and irrational use of antibiotics and low volume of blood obtained for cultures especially among children.

Widal test has been used for over a century in developing countries for diagnosing typhoid fever but it has been reported to have low sensitivity, specificity and positive predictive value. ${ }^{9}$ In the present study, Widal test was positive in $66 \%(33 / 50)$ of the patients. Widal test was positive in 26 of the 33 blood culture positive patients and 7 of blood culture negative patients. Thus the test had sensitivity of $78.78 \%$ and specificity of $58.82 \%$. This corroborates well with data from endemic areas. ${ }^{5,9,15}$ The finding of the present study indicate a low specificity for Widal test. This is very much in consonance with published data especially from endemic areas where there may be high levels of specific and cross reacting antibodies. Though higher sensitivity and specificity for Widal has been reported, its use in endemic areas should not be encouraged. Ideally a fourfold rise in antibody titre in a paired serum is more diagnostic. ${ }^{16}$
Typhidot is a new, inexpensive and reliable serodiagnostic test available commercially and have been reported to have good sensitivity and specificity. In the present study, the sensitivity and specificity of Typhidot was $100 \%$ and $76.5 \%$ respectively. The sensitivity is very much in agreement with other studies, while higher specificities have been reported ${ }^{17}$. A specificity of $76.5 \%$ is comparable to studies from Indian sub-continent who have reported specificity of $77-87 \% \%^{9}, 18$. Typhidot was positive in all blood culture positive patients and in 4 blood culture negative patients. Interestingly, these 4 patients were also positive by Widal test. This finding could be attributed to a) endemicity of typhoid fever in the region indicating preexisting antibody from previous exposure or may be due to sub clinical infection, and this is supported by the fact that these patients were positive for lgG antibodies only, and b) that the patient may have had non-typhoidal fever. All the 50 patients in the study group had strong clinical suspicion of Enteric fever, were treated for the same and recovered completely without requiring any changes in the prescribed antibiotics. Thus, it could be argued that, though Typhidot gave false positive result in 4 cases, these patients may actually have had Salmonella infection, either in the past or sub clinical, which the blood culture failed to detect.

\section{Conclusion :}

It can be concluded that though blood culture is still the gold standard, Typhidot is found to have high sensitivity and good specificity and could be applied as a good alternate in resource poor nation. Further, it is simple to perform, reliable when compared to Widal test and rapid, with results being available in one hour when compared to 48 hours for blood culture and 18 hours for Widal test.

Table 1-Comparison of blood culture with Widal test

\begin{tabular}{|l|c|c|c|c|}
\hline \multirow{3}{*}{ Widal } & \multicolumn{3}{|l|}{ Blood culture } \\
\cline { 2 - 5 } & Positive & Positive & Negative & Total \\
\cline { 2 - 5 } & Negative & 07 & 07 & 33 \\
\cline { 2 - 5 } & Total & 33 & 10 & 17 \\
\hline
\end{tabular}

Sensitivity-78.78\%

Specificity- $58.82 \%$ 
Table 2- Comparison of blood culture with Typhidot

\begin{tabular}{|c|c|c|c|c|}
\hline \multirow{4}{*}{ Typhidot } & \multicolumn{3}{|l|}{ Blood culture } \\
\cline { 2 - 5 } & & Positive & Negative & Total \\
\cline { 2 - 5 } & Negative & 33 & 04 & 37 \\
\cline { 2 - 5 } & Total & 00 & 13 & 13 \\
\hline
\end{tabular}

Sensitivity-100\%

Specificity- $76.58 \%$

\section{References:}

1. Olsen SJ, Pruckler J, Bibb W, Thi My Thanh N, M yTrinh T, ThiM inh N et al. Evaluation of Rapid Diagnostic Tests for Typhoid fever. J Clin Microbial 2004; 42:1885-1889.

2. Begum Z, Hossain Md A, Shamsuzzaman AKM , Ahsan Md M, Musa AKM, Mahmud Md C et al. Evalutaion of Typhidot(IgM) for Early Diagnosis of Typhoid fever. Bangladesh J Med M icrobiol 2009; 3:10 13.

3. Ivanoff B, Levine M M, Lambert PH. Vaccination against typhoid fever, present status. Bull WHO 1994:72(6).957-71.

4. Krishna S, Desai S, Anjana VK, Paranthaaman RG. Typhodot(IgM) as a reliable and rapid diagnostic test for typhoid fever. Ann Trop M ed Pub Health 2011; 4:42-44.

5. Narayanappa D, Sripathi R, Kumar JK, Rajani HS. Comparative study of Dot Enzyme Immunoassay (Typhidot-M) and Widal test in the diagnosis of Typhoid fever. Indian Pediatrics 2009; 47: 331-333

6. Choo KE, Openheimer SJ, Ismail AB, Ong KH. Rapid serodiagnosis of typhoid fever by dot enzyme immunoassay in an endemic area. Clin Infect Dis 1994:19: 172-176.

7. Koneman EW, Allen SD, Janda WM, Schreckenberger PC, Winn WC Colour Atlas and Textbook of Diagnostic M icrobiology. $5^{\text {th }}$ ed.New York: Lippincott; 1997

8. Old DC. Salmonella infection. In: Collee JG, Fraster AG, Marmion BP, Simons a, eds. Mackie and M cCartney practical medical microbiology, $14^{\text {th }}$ ed. New York: Churchil Livingstone; 1996:385-402.

9. Sherwal BI, Dhamija RK, Randhawa VS, Jais M, Kaintura A, Kumar M . A comparative study of Typhidot and Widal test in patients of Typhoid fever. JIACM 2004; 5:244-246.
Table 3- Comparison of Widal test and Typhidot.

\begin{tabular}{|l|c|c|c|c|}
\hline \multirow{3}{*}{ Widal } & \multicolumn{3}{|c|}{ Typhidot } & \\
\cline { 2 - 5 } & & Positive & Negative & Total \\
\cline { 2 - 5 } & Positive & 30 & 03 & 33 \\
\cline { 2 - 5 } & Negative & 07 & 10 & 17 \\
\cline { 2 - 5 } & Total & 37 & 13 & 50 \\
\hline
\end{tabular}

10. Abucejo PE, Capeding M R, Lupsian SP, Arcay J, Sombrero LT, Ruutu P, Herva E. Blood culture confirmed typhoid fever in a provincial hospital in Philippines. Southeast Asian j Trop M ed Public Health 2001; 32:531536.

11. Wain J, Diep ST, BeBay PV, Walsh AL, HaVinh Duong NM et al. Specimen and culture media for the laboratory diagnosis of typhoid fever.J Infect Developing Countries 2008; 2:469-474.

12. Akoh JA. Relative sensitivity of blood and bone marrow culture in typhoid fever. Trop Doct 1991; 21:174-176.

13. Jesudason MV, Sivakuma S. Propective evaluation of a rapid diagnostic test Typhidot for typhoid fever. Indian J M ed Res 2006; 123:513-516

14. Saha M R, Duta P, Palit A, Dutt D, Bhattacharya M K, M itra U et al. A note on incidence of typhoid fever in diverse age groups in Kolkota, India. Jpn J Inf Dis 2003; 56:121-122.

15. Khoharo HK. A comparative study of the Typhidot (Dot-EIA) and Wida test in blood culture positive cases of typhoid fever. Tropical Doctor 2011; 4:136-138.

16. Anagha K, Bhalerao D, Shariar R, Kulkarni S. The easy and early diagnosis of typhoid frver.J Clin Diag Res 2012; 6:198-199.

17. Choo KE, Davis TM, Ismail A, Ibrahim TA, Ghazali WN. Rapid and reliable serological diagnosis of enteric fever: comparative sensitivity and specificity of Typhidot and Typhidot- $M$ tests in febrile M alaysian children. Acta Tropica 1999; 72:175-183.

18. Butta ZA, M ansurali N. Rapid serological diagnosis of pediatric typhoid fever in an endemic area: a prospective comparative evaluation of two dot-enzyme immunoassays and widal test. Am J Trop M ed Hyg 1999; 61:645-647. 